\title{
EFEKTIVITAS UNIT PEMBELAJARAN BERBASIS GUIDED INQUIRY LABORATORY (GIL) UNTUK MENINGKATKAN KETERAMPILAN BERPIKIR KREATIF
}

\author{
Herning Nurdiana ${ }^{1}$, Sajidan $^{2}$, Maridi $^{3}$ \\ Magister Pendidikan Sains, Universitas Sebelas Maret ${ }^{1,2,3}$ \\ Email: dyana.hern@gmail.com
}

\begin{abstract}
Abstrak
Tujuan dari penelitian ini adalah untuk mengetahui keefektifan unit pembelajaran sistem pencernaan manusia berbasis GIL untuk meningkatkan keterampilan berpikir kreatif siswa. Penelitian ini menggunakan rancangan kuasi eksperimen non equivalent control group design yang dilakukan pada masa pandemi covid-19 dengan pembelajaran jarak jauh. Subjek penelitian merupakan siswa SMP kelas VIII semester genap tahun ajaran 2020/2021 yang terbagi menjadi 2 kelas yaitu kelas eksperimen dan kelas kontrol. Hasil penelitian dan pengembangan ini menyatakan bahwa unit pembelajaran sistem pencernaan manusia berbasis GIL dapat meningkatkan meningkatkan keterampilan berpikir kreatif siswa. Hasil uji lanjut independent sample t-test dari gain score kelas eksperimen dan kontrol diperoleh signifikasi sebesar 0,000, berarti terdapat perbedaan antara nilai sebelum dan sesudah diberikan unit pembelajaran, sehingga dapat disimpulkan bahwa penggunaan unit pembelajaran berbasis GIL efektif untuk meningkatkan keterampilan berpikir kreatif siswa. Besar efek yang ditimbulkan oleh penggunaan unit pembelajaran berbasis GIL dilakukan menggunakan analisis effect size menggunakan cohens' $d$ sebesar 1,01, yang artinya pengunaan unit pembelajaran berbasis GIL mempunyai efek yang besar dalam meningkatkan keterampilan berpikir kreatif siswa.
\end{abstract}

Kata Kunci : Unit Pembelajaran, Guided Inquiry Laboratory, Berpikir Kreatif

\begin{abstract}
The purpose of this study is to see the effectiveness of the GIL-based human digestive system unit learning to improve students' creative thinking skills. The study used a quasi-experimental nonequivalent control group design which was carried out during the Covid-19 pandemic by distance learning. The research subjects were junior high school students in class VIII even semester of the 2020/2021 academic year which were divided into 2 classes, namely the experimental class and the control class. The results of this research and development stated that the GIL-based human digestive system unit learning can improve students' creative thinking skills. The results of the independent sample t-test from the gain score of the experimental class and the control class obtained significance of 0.000, meaning that there was a difference between the score before and after the unit learning was given, so it can be concluded that the use of GIL-based learning unit was effective for improving students' creative thinking skills. The total effect caused by the use of GIL-based learning units was carried out using an effect size analysis with cohen's $d$ of 1.01, which implied that the GIL-based unit learning had a great influence in improving students' creative thinking skills.
\end{abstract}

Key Words : Unit Learning, Guided Inquiry Laboratory, Creative Thinking

\section{PENDAHULUAN}

Perkembangan ilmu pengetahuan dan teknologi saat sudah berkembang pesat dari waktu ke waktu, sehingga menjadikan semua pihak dapat mengakses informasi dengan cepat dan nmudah dari berbagai sumber. Hal tersebut menuntut peserta didik untuk memiliki kemampuan dalam memperoleh, dan mengelola informasi yang didapat. Perkembangan abad 21 terjadi peningkat an kemajuan dalam bidang teknologi. Abad 21 merupakan era disrubsi dimana sumber daya manusia mulai digantikan dengan teknologi. Perkembangan tersebut turut serta menyesuaikan tuntutan tercapainya pendidikan abad 21 [1]. Terdapat keterampilan yang diutamakan 
dalam pembelajaran yang dikenal dengan sebutan 4C yaitu berpikir kritis (Critical thinking) dan pemecahan masalah (problem solving), komunikasi (communications) dan kolaborasi (collaboration), serta kreativitas (creativity) dan inovasi (innovation) [2]. Era zaman abad 21 menjadi lebih mudah karena teknologi. Salah satu cara untuk menentukan kemampuan peserta didik dalam menghadapi perkembangan ilmu pengetahuan dan teknologi dapat dilakukan melalui pendidikan. Selain itu, menurut Undang-Undang Nomor 20 tahun 2003 tentang Sistem Pendidikan Nasional, Pasal 3, tujuan pendidikan nasional adalah mengembangkan potensi peserta didik agar menjadi manusia yang beriman dan bertakwa kepada Tuhan Yang Maha Esa, berakhlak mulia, sehat, berilmu, cakap, kreatif, mandiri, dan menjadi warga negara yang demokratis serta bertanggung jawab.

Permasalahan yang terjadi pada pembelajaran di sekolah menengah pertama perlu dikaji dan diselesaikan agar pembelajaran dapat berjalan lebih baik dalam menghadapi tuntutan abad 21 . Salah satu kompetensi dari keterampilan abad 21 yang dapat ditingkatkan pada jenjang sekolah menengah pertama adalah keterampilan berpikir kreatif. Keterampilan berpikir kreatif adalah kemampuan individu untuk menemukan gagasan baru, kemungkinan baru, penemuan baru yang menggunakan pikirannya berdasarkan orisinalitas dalam pekerjaannya [3]. Keterampilan berpikir kreatif adalah kegiatan yang menghasilkan gagasan baru, memungkinkan sesuatu untuk dilihat dari sudut pandang yang berbeda, imajinatif, memiliki potensi untuk menghasilkan gagasan dan perubahan yang maju, mampu menghasilkan banyak ide serta terampil dalam memecahkan suatu permasalahan [4]. Terdapat 4 Indikator keterampilan berpikir kreatif yang dikembangkan dari Torrance dan Gildford yaitu; Fluency (berpikir lancar), flexibility (berpikir luwes), originality (keaslian), elaboration (merinci). Bedasarkan penelitian dari Nurdiana, H, 2020 bahwa keterampilan berpikir kreatif siswa SMP negeri 8 kota surakarta dalam pembelajaran IPA masih tergolong rendah. Terdapat beberapa cara untuk meningkatkan keterampilan berpikir kreatif siswa SMP dalam pembelajaran, salah satunya dengan penguunaan unit pembelajaran berbasis model.

Unit pembelajaran merupakan suatu bahan ajar yang memudahkan guru mempelajari konten dan cara mengajarkannya. Komponen-komponen di dalam unit pembelajaran ini dikembangkan dengan tujuan agar guru dapat dengan mudah memfasilitasi peserta didik memahami materi, melakukan percobaannya, sekaligus mendorong peserta didik mencapai kemampuan berpikir tingkat tinggi yaitu keterampilan berpikir kreatif [5]. Basis model yang cocok digunakan dalam unit pembelajaran adalah menggunakan model Guided inquiry Laboratory. Guided Inquiry Laboratory (GIL) merupakan level inkuiri yang menjelaskan bahwa siswa dapat lebih mandiri dalam mengembangkan dan mendesain rencana percobaan serta mengumpulkan data [6]. Siswa juga dituntut untuk mampu menganalisis data dengan menggunakan grafik. Terdapat 5 Sintaks GIL menurut wenning yaitu; observasi, manipulasi, generalisasi, verifikasi, dan aplikasi.

Maka dari itu, tujuan penelitian ini adalah untuk mendeskripsikan keefektifan unit pembelajaran berbasis GIL untuk meningkatkan keterampilan berpikir kreatif siswa SMP. Pembelajaran IPA menggunakan unit pembelajaran berbasis GIL yang dapat meningkatkan 
keterampilan berpikir kreatif siswa, selain itu juga memfasilitasi siswa dalam pembelajaran yang lebih menekankan pada pembelajaran mandiri dan guru berperan sebagai fasilitator.

\section{METODE}

Pelaksanaan pembelajaran menggunakan sistem pembelajaran jarak jauh dengan bahan ajar berupa unit pembelajaran berupa tampilan e-book. Pembelajaran di kelas dilakukan bedasarkan perangkat pembelajaran yang terdapat pada unit pembelajaran untuk guru yang dilengkapi dengan rekomendasi langkah-langkah kegiatan pembelajaran menggunakan sintaks GIL dan kunci jawaban soal, sedangkan siswa menggunakan unit pembelajaran untuk siswa yang didalamnya terdapat LKPD, latihan soal keterampilan berpikir kreatif dan uraian materi.

Uji lapangan operasional unit pembelajaran berbasis GIL ini dilakukan untuk mendapatkan data berkaitan dengan produk yang dikembangkan sehingga diketahui keefektifan dan keunggulan dari produk tersebut. Uji lapangan operasional unit pembelajaran berbasis GIL pada materi sistem pencernaan manusia menggunakan rancangan kuasi eksperimen non equivalent control group design [7]. Desain penelitian disajikan dalam tabel 1 seperti berikut.

Tabel 1. Non Equivalent Control Group

\begin{tabular}{lccc}
\multicolumn{4}{c}{ Design } \\
\hline Group & Pretest & Perlakuan & Posttest \\
\hline $\begin{array}{l}\text { Kelas } \\
\text { Eksperimen }\end{array}$ & $\mathrm{O}_{1}$ & $\mathrm{X}_{1}$ & $\mathrm{O}_{2}$ \\
\hline $\begin{array}{l}\text { Kelas } \\
\text { Kontrol }\end{array}$ & $\mathrm{O}_{3}$ & $\mathrm{X}_{2}$ & $\mathrm{O}_{4}$ \\
\hline
\end{tabular}

Keterangan :

$\mathrm{O}_{1}=$ Hasil pretest kelas eksperimen

$\mathrm{O}_{2} \quad=$ Hasil posttest kelas eksperimen

$\mathrm{X}_{1}=$ Perlakuan kelas eksperimen menggunakan unit pembelajaran berbasis $G I L$
$\mathrm{X} 2=\begin{aligned} & \text { Perlakuan kelas kontrol } \\ & \text { menggunakan bahan ajar yang ada di } \\ & \text { sekolah }\end{aligned}$

Subjek penelitian ini merupakan 60 siswa semester ganjil kelas VIII tahun ajaran 2020/2021 di SMP Negeri 8 Kota Surakarta yang dipilih menggunakan teknik purposive sampling dan terbagi dalam 2 kelompok yaitu kelompok kelas eksperimen dan kelompok kelas kontrol. Pretest dan posttest dilakukan terhadap siswa untuk mengetahui dampak penerapan unit pembelajaran berbasis GIL. Deskripsi hasil pretest dilakukan untuk mengetahui keterampilan berpikir kreatif siswa sebelum diberi perlakuan menggunakan unit pembelajaran berbasis GIL.

Uji keefektifan digunakan untuk menghitung peningkatan keterampilan berpikir kreatif siswa mengguanakan teknik normalized gain atau biasa disebut dengan gain score [8]. Gain score dapat dihitung menggunakan rumus sebagai berikut :

$$
g>=\frac{S \text { post }-S \text { pre }}{S \max -S \text { pre }}
$$

Keterangan :

$\langle g\rangle \quad=$ faktor gain

$S$ post $=$ skor rata-rata posttest $(\%)$

S pre = skor rata-rata pretest $(\%)$

$S$ max $=$ skor maksimal $=100 \%$

Langkah selanjutnya setelah mendapatkan data hasil pengolahan gain score, kemudian menentukan kriteria efektifitas penggunaan unit pembelajaran untuk meningkatkan keterampilan berpikir kreatif bedasarkan kriteria seperti pada tabel 2 berikut ini :

Tabel 2. Kriteria Hasil Gain Score Ternormalisasi

\begin{tabular}{cc}
\hline Nilai & Kategori \\
\hline $0,7<\mathrm{g}<1$ & Tinggi \\
\hline $0,3<\mathrm{g}<0,7$ & Sedang \\
\hline $0<\mathrm{g}<0,3$ & Rendah \\
\hline & Sumber: $[8]$
\end{tabular}


Setelah analisis gain score, dilakukan uji lanjut digunakan untuk menentukan signifikansi peningkatan keterampilan berpikir kreatif siswa yang dilakukan menggunakan software SPSS. Sebelum menggunakan teknik analisis data ini, ada persyaratan yang harus dipenuhi, sehingga peneliti diijinkan untuk menggunakan teknik analisis, yaitu uji normalitas datadan uji homogenitas data. Pengujian normalitas data tersebut menggunakan uji Kolmogorov-Smirnov sedangkan pengujian homogenitas menggunakan uji Levene Statistic [9]. Setelah uji normalitas dan homogenitas hasil yang diperoleh adalah data berdistribusi normal dan homogen selanjutnya uji lanjut data dianalisis menggunakan uji statistik parametrik yaitu Independent Sample T-test menggunakan software SPSS 22 for Windows 7. Pengujian yang terakhir adalah uji effect size. Uji effect size merupakan besarnya efek yang ditimbulkan oleh parameter yang telah diuji dalam pengujian hipotesis. Nilai atau besarnya keefektifan unit pembelajaran kaitannya dengan meningkatkan keterampilan berpikir kreatif [10]. Hasil analisis uji effect size Cohend's $d$ dari hasil $T$ Independent sample menggunakan bantuan kalkulator online pada website https://www.socscistatistics.com/effectsize 1. Setelah didapatkan hasil dari perhitungan pada website tersebut kemudian hasilnya dapat dikategorikan seperti pada Tabel 3 dibawah ini:

Tabel 3. Kategori Effect Size

\begin{tabular}{cc}
\hline Hasil perhitungan & Kategori \\
\hline Kecil & 0,2 \\
\hline Sedang & 0,5 \\
\hline Besar & 0,8 \\
\hline Sangat besar & 1,3 \\
\hline & Sumber: [10]
\end{tabular}

HASIL DAN PEMBAHASAN

Efektivitas unit pembelajaran berbasis GIL dapat diketahui dari hasil analisis gain score ternormalisasi pada kelas eksperimen dan kontrol. Untuk menguji hasil gain score diperlukan nilai pretest dan posttest. Hasil skor pretest dan posttest kelas eksperimen dan kontrol dapat dilihat pada Tabel 4 berikut.

Tabel 4. Hasil Skor Pretest dan Posttest Kelas Eksperimen dan Kontrol

\begin{tabular}{|c|c|c|c|c|}
\hline Kelompok & $n$ & $\begin{array}{l}\text { Nilai } \\
\text { Min }\end{array}$ & $\begin{array}{l}\text { Nilai } \\
\text { Max }\end{array}$ & $\begin{array}{l}\text { Rata- } \\
\text { rata }\end{array}$ \\
\hline $\begin{array}{l}\text { Pretest } \\
\text { Eksperimen }\end{array}$ & 30 & 28,12 & 62,50 & 46,70 \\
\hline $\begin{array}{l}\text { Pretest } \\
\text { Kontrol }\end{array}$ & 30 & 28,12 & 62,50 & 47,08 \\
\hline $\begin{array}{l}\text { Posttest } \\
\text { Eksperimen }\end{array}$ & 30 & 78,12 & 96,87 & 89,06 \\
\hline $\begin{array}{l}\text { Postest } \\
\text { Kontrol }\end{array}$ & 30 & 65,62 & 93,75 & 82,19 \\
\hline
\end{tabular}

Bedasarkan data pada tabel di atas dapat dilihat bahwa kemampuan awal pada kelas eksperimen dan kontrol memiliki rata-rata nilai yang hampir sama sebesar 46,70 pada kelas eksperimen dan 47,08 pada kelas kontrol. Setelah diberi perlakuan berupa penggunaan unit pembelajaran pada kelas eksperimen hasil rata-rata nilai posttest pada kelas eksperimen meningkat pesat menjadi 89,06, sedangkan pada kelas kontrol yang tidak diberikan unit pembelajaran sebagai bahan ajar nilai rataratanya hanya 82,19 . Peningkatan nilai keterampilan berpikir kreatif siswa dihitung menggunakan rumus gain score [8].

$$
<g>=\frac{\text { s post }-s \text { pre }}{\text { scormax }- \text { spre }}
$$

Hasil analisis gain score menggunakan rumus tersebut dapat dilihat pada Tabel 5 berikut ini.

\begin{tabular}{|c|c|c|}
\hline \multicolumn{3}{|c|}{ Score Nilai Pretest dan Posttest } \\
\hline Kelas & $\begin{array}{c}\text { Gain } \\
\text { Score }\end{array}$ & Kategori \\
\hline Eksperimen & 0,77 & Tinggi \\
\hline Control & 0,64 & Seda \\
\hline
\end{tabular}

Tabel 5. Hasil Analisis Rata-Rata Gain

Sumber: Data diolah menggunakan aplikasi SPSS 22 
Bedasarkan tabel tersebut, dapat dilihat bahwa gain score kelas eksperimen lebih tinggi dengan perolehan gain skor rata-rata sebesar 0,77 masuk kategori tinggi dari pada kelas kontrol yang hanya 0,64 dan masuk dalam kategori sedang. Penggunaan unit pembelajaran pada siswa memiliki dampak yang baik sejalan dengan penelitian yang menyatakan bahwa penggunaan unit pembelajaran berbasis GIL pada kelas eksperimen memberikan peningkatan pada gain score kelas yang diberi perlakuan atau kelas eksperimen [11].

Setelah melihat hasil rata-rata gain score dari kedua kelas tersebut, maka selanjutnya dilakukan uji lanjut menggunakan software SPSS untuk mengetahui keefektifan unit pembelajaran berbasis GIL untuk meningkatkan keterampilan berpikir kreatif siswa. Uji prasyarat dilakukan terlebih dahulu menggunakan uji normalitas pada gain score siswa kelas eksperimen dan kontrol menggunakan uji kolmogrofsmirnov, sedangkan untuk uji homogenitas menggunakan Levene's. Apabila data berdistribusi normal dan homogen maka akan dilakukan uji lanjut menggunakan Independent sample T-test [12]. Hasil uji normalitas dapat dilihat pada Tabel 6 berikut ini.

Tabel 6. Hasil Uji Normalitas Gain Score Kelas Eksperimen dan Kontrol

\begin{tabular}{lcc}
\hline Kelas & $\boldsymbol{D f}$ & Sig \\
\hline Eksperimen & 30 & 0,064 \\
& & \\
\hline Kontrol & 30 & 0,163 \\
\hline \multicolumn{2}{c}{ Sumber: Data diolah menggunakan aplikasi SPSS 22}
\end{tabular}

Hasil uji normalitas dengan uji KolmogrovSminorv pada kelas eksperimen maupun kontrol dapat disimpulkan bahwa antara kelas eksperimen maupun kelas kontrol nilai sig yang didapat masing-masing > 0,05 . Hal ini menunjukkan bahwa rata-rata Gain score pretest dan posttest keterampilan berpikir kreatif pada kelas eksperimen maupun kontrol berdistribusi normal. Selanjutnya dilakukan uji homogenitas dapat dilihat pada Tabel 7 berikut ini.

Tabel 7. Hasil Uji Homogenitas Gain Score Kelas Eksperimen dan Kontrol

\begin{tabular}{lcc}
\hline Data & $\begin{array}{c}\text { Levene } \\
\text { Statistic }\end{array}$ & Sig \\
\hline $\begin{array}{l}\text { Rata-rata } \\
\text { Gain Score }\end{array}$ & 3,259 & $\mathbf{0 , 0 7 6}$ \\
\hline \multicolumn{2}{c}{ Sumber: Data diolah menggunakan aplikasi SPSS 22 }
\end{tabular}

Bedasarkan tabel tersebut, dapat dilihat bahwa nilai Sig, 0,076 > 0,05 maka data dikatakan homogen. Uji prasyarat berupa uji normalitas dan homogenitas pada data rata-rata gain score keterampilan berpikir kreatif pada kelas eksperimen maupun kontrol menunjukkan data berdistribusi normal dan homogen. Maka selanjutnya dilakukan uji Independent sample T-test dilakukan dengan membaca data hitungan pada lajur kolom Equal variance assumed dapat dilihat pada Tabel 8 berikut.

\begin{tabular}{|c|c|c|c|}
\hline \multicolumn{3}{|c|}{$\begin{array}{c}\text { Tabel 8. Hasil Uji Independent Sample t- } \\
\text { test terhadap Gain Score Kelas } \\
\text { Eksperimen dan Kontrol }\end{array}$} & \\
\hline \multirow[t]{2}{*}{ Data } & & -Tes & \\
\hline & $t$ & $d f$ & $\begin{array}{c}\operatorname{Sig}(2 \\
\text { tailed })\end{array}$ \\
\hline $\begin{array}{l}N \text {-Gain Equal } \\
\text { Variances } \\
\text { assumed }\end{array}$ & 3,897 & 58 & 0,000 \\
\hline
\end{tabular}

Hasil uji lanjut menggunakan uji Independent Sample T-test memberikan hasil bahwa nilai sig(2 tailed) sebesar $0,000<0,05$ dapat disimpulkan bahwa terdapat perbedaan Gain score rata-rata antara kelas eksperimen dan kontrol. Perbedaan ini menunjukkan bahwa unit pembelajaran yang dikembangkan dan diterapkan pada kelas eksperimen efektif untuk meningkatkan keterampilan berpikir kreatif siswa. Besarnya keefektifan unit 
pembelajaran yang dikembangkan dalam meningkatkan keterampilan berpikir kreatif dapat dilakukan dengan uji effect size. Hasil analisis uji effect size Cohend's $d$ dari hasil $T$ Independent sample menggunakan bantuan kalkulator online pada website https://www.socscistatistics.com/effectsize L dapat dilihat pada Tabel 9 berikut ini.

Tabel 9. Hasil Analisis Uji Effect Size

\begin{tabular}{lcccc}
\hline Kelas & Mean & $\begin{array}{c}\text { Std. } \\
\text { Deviation }\end{array}$ & $\boldsymbol{n}$ & $\begin{array}{c}\text { Cohend's } \\
\boldsymbol{d}\end{array}$ \\
\cline { 1 - 4 } Eksperimen & 0,770 & 0,103 & 30 & $\mathbf{1 , 0 1}$ \\
\cline { 1 - 3 } Kontrol & 0,641 & 0,148 & 30 & \\
\hline Sumber: Data diolah menggunakan aplikasi kalkulator effect size
\end{tabular}

Bedasrkan Tabel 9 besarnya pengukuran pada hasil tersebut $>0,8$ dan masuk dalam kategori besar, sehingga dapat disimpulkan bahwa unit pembelajaran yang dikembangkan mengindikasikan adanya dampak yang besar dari penerapan unit pembelajaran yan dikembangkan pada aspek-aspek keterampilan berpikir kreatif siswa. Penggunaan bahan ajar berupa modul yang dapat meningkatkan keterampilan berpikir kreatif memiliki effect size Cohen's d sebesar 1,01 dengan kategori besar [10]. Hasil effect size yang diperoleh merupakan dampak dari perlakuan yan diberikan kepada variabel yang ingin dikembangkan. Besarnya pengukuran pada hasil tersebut $>0,8$ dan masuk dalam kategori besar, sehingga dapat disimpulkan bahwa unit pembelajaran yang dikembangkan mengindikasikan adanya dampak yang besar dari penerapan unit pembelajaran yan dikembangkan pada aspek-aspek keterampilan berpikir kreatif siswa [13]. Penggunaan bahan ajar berupa modul yang dapat meningkatkan keterampilan berpikir kreatif memiliki effect size Cohen's $\mathrm{d}$ sebesar 1,02 dengan kategori besar. Hasil effect size yang diperoleh merupakan dampak dari perlakuan yan diberikan kepada variabel yang ingin dikembangkan.
Hasil perolehan effect size dari penggunaan unit pembelajaran pada kelas eksperimen dibandingkan dengan kelas kontrol dipengaruhi oleh beberapa faktor. Menurut penelitian terdahulu kondisi fisik pada siswa merupakan faktor internal seperti kemampuan intelektual, emosional, motivasi diri dan kesehatan. Sifat kepribadian siswa mempengaruhi proses berpikir dalam mengekspresikan perasaan siswa untuk berkontribusi pada pembelajaran dan kemampuan berpikirnya. Terdapat dua faktor utama karakteristik psikologis yaitu sikap terhadap pembelajaran dan motivasi. Sikap terhadap pembelajaran mengacu pada kemampuan siswa menunjukkan kepuasan, kesepakatan, dan ketidaksepakatan terhadap lingkungan guru, kegiatan belajar, teman sekelas, dan lingkungan kelas, sedangkan motivasi mengacu pada antusiasme, kemauan dan niat siswa mencapai tujuan pembelajaran [14].

Faktor eksternal yang mempengaruhi keterampilan berpikir kreatif siswa salah satunya adalah dari lingkungan kelas. Pembelajaran yang berlangsung dalam lingkungan kelas berdampak pada kondis suasana fisik dan psikologis yang dapat mempengaruhi cara berpikir siswa secara kreatif. Hal tersebut terjadi karena pengelolaan pembelajaran kurang efektif dalam mengatur lingkungan kelas untuk mendukung sikap, perasaan, dan kemampuan berpikir siswa.

\section{SIMPULAN}

Simpulan dari penelitian ini adalah unit pembelajaran berbasis GIL pada materi sistem pencernaan manusia efektif untuk meningkatkan keterampilan berpikir kreatif siswa kelas VIII SMP dilihat dari peningkatan gain score yang lebih tinggi pada kelas eksperimen. Hasil uji lanjut Independent Sample t- Test menggunakan Software SPSS 22 juga menunjukkan hasil signifikasi 0,00 yang berarti terdapat 
perbedaan antara kelas eksperimen dan kelas kontrol. Perbedaan tersebut menunjukkan bahwa produk berupa unit pembelajaran yang dikembangkan di kelas eksperimen efektif untuk meningkatkan keterampilan berpikir kreatif siswa. Nilai atau besarnya keefektifan unit pembelajaran keitannya dengan meningkatkan keterampilan berpikir kreatif dapat diketahui menggunakan uji effect size. Hasil analisis uji effect size dari hasil Independent sample $t$ - Test menggunakan bantuan kalkulator online pada website https://www.socscistatistics.com/effectsize I didapatkan hasil Cohend's $d$ sebesar 1,01. Besarnya pengukuran pada hasil tersebut > 0,8 dan masuk dalam kategori besar, sehingga dapat disimpulkan bahwa unit pembelajaran yang dikembangkan mengindikasikan adanya dampak yang besar dari penerapan unit pembelajaran yan dikembangkan pada aspek-aspek keterampilan berpikir kreatif siswa [13].

\section{DAFTAR ISI}

[1] R. Hidayah, "CRITICAL THINKING SKILL: KONSEP DAN INDKATOR PENILAIAN," $J$. Taman Cendekia, vol. 01, no. 02, pp. 127-133, 2017.

[2] Bernie Trilling \& Charles Fadel (2009), 21st Century Skills: Learning for Life in Our Times. 2009.

[3] A. M. Daud, J. Omar, P. Turiman, and K. Osman, "Creativity in Science Education," Procedia - Soc. Behav. Sci., vol. 59, pp. 467-474, 2012, doi: 10.1016/j.sbspro.2012.09.302.

[4] K. Ülger, "Öğrencilerin Yaratici Düşünme Ve Eleştirel Düşünme Becerileri Arasindaki Ilişki," Hacettepe Egit. Derg., vol. 31, no. 4, pp. 695-710, 2016, doi: 10.16986/HUJE.2016018493.

[5] A. Sulaeman, A, Y. Puspitaningsih, dan H. Maulani, A, Unit Pembelajaran

(Program
Pengembangan Keprofesian

Berkelanjutan Melalui Peningkatan Kompetensi Pembelajaran Berbasis Zonasi) Mata Pelajaran IPA, vol. 53, no. 9. Jakarta: Direktorat Jendral Guru dan Tenaga Kependidikan, 2019.

[6] C. J. Wenning, "The Levels of Inquiry Model of Science Teaching," J. Phys. Tchr. Educ. Online, vol. 6, no. 2, pp. 9-16, 2011.

[7] J. . Creswell, RESEARCH DESIGN Pendekatan Kualitatif, Kuantitatif, dan Mixed. Yogyakarta: Pustaka Pelajar, 2012.

[8] R. Hakke, Analyzing change/Gain Score. Indiana: Indana University, 1999.

[9] E. Sudibyo, B. Jatmiko, and W. Widodo, "The Effectiveness of CBL Model to Improve Analytical Thinking Skills the Students of Sport Science," Int. Educ. Stud., vol. 9, no. 4, p. 195, 2016, doi: 10.5539/ies.v9n4p195.

[10] G. M. Sullivan and R. Feinn, "Using Effect Size - or Why the P Value Is Not Enough ," J. Grad. Med. Educ., vol. 4, no. 3, pp. 279-282, 2012, doi: 10.4300/jgme-d-12-00156.1.

[11] A. Febri, "Pengembangan Unit Pembelajaran Mekanika Berbasis Guided Inquiry Lab untuk Meningkatkan Keterampilan Berpikir Kreatif Siswa SMP," Universitas Sebelas Maret, 2020.

[12] N. Sudjana, Penilaian Hasil Proses Belajar Mengajar. Bandung: PT Remaja Rosdakarya, 2009.

[13] P. G. P. Anjarwati, S. Sajidan, and B. A. Prayitno, "Problem-Based Learning Module of Environmental Changes to Enhance Students' Creative Thinking Skill," Biosaintifika J. Biol. Biol. Educ., vol. 10, no. 2, pp. 313-319, 2018, doi: 10.15294/biosaintifika.v10i2.12598.

[14] P. Budsankom, T. Sawangboon, 
Damrongpanit, and J. Chuensirimongkol, "Factors affecting higher order thinking skills of students: A meta-analytic structural equation modeling study," Acad. journals, vol. 10, no. 19, pp. 2639-2652, 2015, doi: 10.5897/ERR2015. 